\title{
Thermosetting nanocomposites with high carbon nanotube loadings processed by a scalable powder based method
}

\author{
Tomi M. Herceg ${ }^{\mathrm{a}, \mathrm{b}, \mathrm{c}}$, Sung-Ho Yoon ${ }^{\mathrm{c}, \mathrm{d}}$, M. Shukur Zainol Abidin ${ }^{\mathrm{c}, \mathrm{e}}$, Emile S. Greenhalgh ${ }^{\mathrm{c}, \mathrm{e}}$, \\ Alexander Bismarck ${ }^{\mathrm{b}, \mathrm{c}, \mathrm{f}}$, Milo S.P. Shaffer ${ }^{\mathrm{a}, \mathrm{c}}$ \\ ${ }^{a}$ Department of Chemistry, Imperial College London, UK \\ ${ }^{b}$ Department of Chemical Engineering, Imperial College London, UK \\ ${ }^{\mathrm{c}}$ The Composites Centre, Imperial College London, UK \\ ${ }^{\mathrm{d}}$ Solid Mechanics and Materials Engineering, Oxford, UK \\ ${ }^{\mathrm{e}}$ Department of Aeronautics, Imperial College London, UK \\ ${ }^{\mathrm{f}}$ Institute for Materials Chemistry and Research, University of Vienna, Austria
}

\begin{abstract}
A powder based processing route was developed to allow manufacturing of thermosetting nanocomposites with high (20 wt \%) carbon nanotube (CNT) loading fractions. Adaptation of high shear mixing methods, as used in thermoplastic processing, ensured that the CNTs were well distributed and dispersed even at the highest loadings. By minimising flow distances, compression moulding of powders ensured that the CNTs did not agglomerate during consolidation, and yielded a percolated CNT network in a nanocomposite with excellent electrical and thermal conductivities of $67 \mathrm{~S} \mathrm{~m}^{-1}$ and $0.77 \mathrm{~W} \mathrm{~m}^{-1} \mathrm{~K}^{-1}$, respectively. Unusually, the CNTs provided effective mechanical reinforcement at even the highest loadings; embrittlement is minimised by avoiding large scale inhomogeneities and the maximum measured Young's modulus (5.4 GPa) and yield strength (90 MPa) could make the nanocomposite an attractive matrix for continuous fibre composites. The macromechanical measurements were interpolated using micromechanical models that were previously successfully applied at the nanoscale.
\end{abstract}

\section{Introduction}

Carbon nanotubes (CNTs) have been scrutinized for over a decade as a constituent in thermoset based nanocomposites (NCs) due to their exceptional intrinsic multifunctional 
properties [1]. One of the major challenges in the field has been to distribute and disperse high loading fractions of CNTs in epoxy resins by a route that is scalable to high throughput. The choice of processing route is critical to determining the microstructure and hence properties of the composite; agglomeration of CNTs is often particularly problematic [2].

Large CNT loadings have been relatively easily achieved in thermoplastics by shear mixing $[3,4]$, as they benefit from broad processing windows. For thermosets, traditional dispersion techniques such as simple stirring and sonication have produced good quality NCs for low CNT loadings, but have been ineffective at CNT volume fractions beyond a few percent [57]. At high loadings, techniques such as layer-by-layer (LBL) deposition [8], resin infiltration of buckypapers [9], drawing, aligning and stacking CNT sheets [10] or resin infusing continuous and aligned CNT forests $[11,12]$ have been successfully employed to manufacture high quality thermosetting composites. In one promising example, highly aligned and crystalline CNT arrays were infused with epoxy and shown to be an effective reinforcement (16.5 wt\%), improving stiffness from 2.5 to $20.5 \mathrm{GPa}$, strength from 89 to 231 $\mathrm{MPa}$, and electrical conductivity $\left(\sigma_{\mathrm{DC}}\right)$ similar to that of amorphous carbon $\left(\sim 10^{3} \mathrm{Sm}^{-1}\right)[10]$.

Three roll milling has been identified as a promising approach for dispersing high fractions of CNTs in epoxy resins in large volumes [13]. This technique has been successfully used to produce NCs containing up to $5 \mathrm{wt} \%$ multi walled carbon nanotubes (MWCNTs) that also have enhanced mechanical, electrical and thermal properties [14]. The highest CNT loading reported in epoxy with this method is $8 \mathrm{wt} \%$ [15], but since the aim was maximum $\sigma_{\mathrm{DC}}$, the $\mathrm{NC}$ was only moderately sheared to allow the formation of a dense, interconnected CNT network, which is not optimal for mechanical performance. However, in principle, mixing CNTs and thermosets using large shear forces as done in thermoplastic based NCs could yield good CNT dispersions at high loadings. 
This work draws on the potential of readily scalable, shear mixing techniques to make excellent isotropic dispersions of CNTs in epoxy matrices. The aim was to avoid agglomeration on the $10-100 \mu \mathrm{m}$ scale, which is typically the limitation to introducing large CNT fractions in the resin. The approach uses thermoplastic processing techniques, specifically extrusion; the excellent dispersion was maintained during consolidation by minimising the flow distance using a powder-based, vacuum-assisted compression moulding technique. The resulting NCs were characterised mechanically, electrically and thermally to determine the success of the processing route and the resulting properties.

\section{Experimental}

\subsection{Materials and nanocomposite preparation}

The CNTs (NC 7000, Nanocyl ${ }^{\mathrm{TM}}$ ) were industrial grade, highly entangled and catalytically grown. According to the manufacturer's datasheet, the CNTs were about $1.5 \mu \mathrm{m}$ long, $10 \mathrm{~nm}$ in diameter and contained $10 \mathrm{wt} \%$ metal oxide catalyst; the catalyst content was confirmed by thermogravimetric analysis (TGA) in air. Raman spectroscopy confirmed [16] a large proportion of defects in the otherwise graphitic walls $\left(\mathrm{I}_{\mathrm{G}} / \mathrm{I}_{\mathrm{D}}=0.86\right)$. The matrix consists of a Bisphenol-A and Bisphenol-F epoxy blend (EPIKOTE ${ }^{\mathrm{TM}}$ 1001) cured using a dicyandiamide (Dyhard® 100S) hardener with an average particle size of $10 \mu \mathrm{m}$. Both components were generously provided by Hexcel Composites (Duxford, UK).

When choosing this resin system, there were two considerations. The first was to upgrade the properties of a low-cost resin so that it could be used for structural applications. The second was that the $\mathrm{NC}$ should be moulded as a fine powder in order to minimise flow distances during consolidation thus minimising re-agglomeration and difficulties associated with high viscosities. EPIKOTETM 1001 was chosen because it is a relatively inexpensive coating resin and remained as a powder at ambient temperatures rather than fusing. Dicyandiamide 
(DICY), a latent curing agent, provides a broad processing window so that CNTs can be initially mixed into the epoxy at high temperature and shear without the undesired onset of gelation [17].

DICY was weighed out at $4 \%$ by weight of resin and 2.4, 4.8, 9.1, 13 and $20 \%$ CNTs by weight of the composite. Control samples were prepared without any CNTs. The raw materials were mixed using a co-rotating twin screw extruder (PRISM TSE 16 TC, Thermo Scientific) in two passes at speeds of 100-200 RPM (residence time of 2-5 minutes) and barrel temperature of $70-125^{\circ} \mathrm{C}$ to maintain constant torque.

The NC product was then ground into a powder using a cryogenic ball mill (Cryomill, Retsch). The milling process was adjusted by varying the duration and frequency of the grinding cycles to reduce the median powder particle size, and obtain a narrow particle size distribution. The powder particle sizes were measured from surfactant stabilised suspensions $(0.5 \%$ Triton $\mathrm{X}-100$ by weight of water) in deionised water using a laser diffractometer (Mastersizer 2000, Malvern Instruments), which produces a distribution of particle diameters based on refraction angles, with larger particles having smaller refraction angles.

The powder was consolidated by compression moulding into dogbones according to the ASTM D638 Type V specification with a $3 \times 3 \mathrm{~mm}^{2}$ gauge section. The mould assembly containing the powder was covered with peel ply, breather cloth, and a vacuum bagging sheet sealed to a metal plate with tacky tape. Vacuum was applied for 30 min to remove air, then held while the mould was heated to $125^{\circ} \mathrm{C}$ on the platen of a hydraulic hot press (Moore Presses) to allow the powder to melt. Once the desired temperature was reached, 14.5 bar of pressure was applied and the mould was heated to $150^{\circ} \mathrm{C}$ to cure for $12 \mathrm{~h}$. The control sample was cured following the same temperature profile, but in a vacuum oven and without a 
plunger since the low viscosity epoxy melt flowed easily; overflow during degassing was thus prevented.

\subsection{Nanotube and nanocomposite microscopical characterisation}

SEM (LEO Gemini 1525 FEG, Carl Zeiss) and TEM (2100, JEOL) of over 100 CNTs were used to determine their length and diameter distributions, respectively. Samples for TEM were prepared by dipping a holey carbon grid into an ethanol solution containing as-received nanotubes dispersed by bath sonication (USC300T, VWR), and imaged at an accelerating voltage of $200 \mathrm{kV}$ in bright field. Samples for measuring CNT lengths by SEM were prepared by dissolving in acetone the uncured resin from NCs that had been extruded and cryomilled, filtering $(0.1 \mu \mathrm{m}$ hydrophilic PTFE membrane, Millipore) and washing the nanotubes with acetone (ACS, VWR), suspending them in dimethylformamide (DMF) (Rectapur, VWR) by bath sonication and pipetting the suspension onto polished SEM stubs. Images were collected at an accelerating voltage of $10 \mathrm{kV}$, and analysed with the Image $\mathrm{J}$ software.

SEM of fractured tensile samples was also used to characterise the dispersion and distribution of the CNTs in the epoxy system and measure their pull-out length. Fractured samples were mounted onto aluminium stubs and sputter coated with a $5 \mathrm{~nm}$ thick layer of chromium to prevent charging. The specimens with the highest CNT loading were sufficiently conductive and were not sputter coated so as to allow observation of the CNT-resin interface. Samples were imaged at an accelerating voltage of $3 \mathrm{kV}$.

The morphology of the NC microstructure was characterised by differential interference contrast (DIC) optical reflective microscopy (AX10 with AxioVision, Zeiss) using fragments from the grips of tensile test specimens that were mounted in epoxy, then ground and polished to $1 \mu \mathrm{m}$ with a rotary polishing machine (Motopol 12, Buehler). 


\subsection{Chemical and physical characterisation}

The composition of the NCs was determined by TGA (Pyris 1, PerkinElmer) in $\mathrm{N}_{2}$ at a ramp rate of $5^{\circ} \mathrm{C} / \mathrm{min}$ from 100 to $850^{\circ} \mathrm{C}$ using segments taken from spent mechanical test specimens. Densities of the NC dogbones were measured by the gas displacement method with a pycnometer (Accupyc 1330, Micrometrics GmbH).

The curing behaviour of the $\mathrm{NC}$ was investigated using differential scanning calorimetry (DSC) (TA Q2000, TA Instruments). The extent of reaction was determined from integrating the heat flow against time as measured from isothermal scans at $150^{\circ} \mathrm{C}$ [18] and normalising it to the integrated heat flow of the control sample. The heat flows were normalised for the mass fraction of resin, as the CNTs are not believed to participate in the crosslinking reaction. The glass transition temperature $\left(\mathrm{T}_{\mathrm{g}}\right)$ of the cured NCs was measured from dynamic DSC scans at $10^{\circ} \mathrm{C} / \mathrm{min}$ between 20 and $150^{\circ} \mathrm{C}$.

Samples for conductivity measurements were sectioned from the grip regions of spent mechanical test specimens and polished to remove griping damage. The electrical conductivities in three axes were deduced from volume resistances measured with a two point probe and an ohm meter (DM9C, Amprobe). Silver paste was applied to the probe and the contact points on each sample to minimise contact resistance. The thermal conductivity (k) was calculated from the thermal diffusivity measured using a Xenon light flash system (LFA 447 Nanoflash®, Netzsch Instruments, Inc.).

\subsection{Nanocomposite mechanical characterisation}

The NC dog bone samples were polished to remove any surface imperfections present from the moulding process. Strain gauges (FLK-1-11, TML) were glued to the working region of the dog bones with cyanoacrylate glue before tensile testing in an Instron 4505 screw driven machine at a speed of $0.5 \mathrm{~mm} / \mathrm{min}$. At least five samples were tested for each CNT loading. 
The fracture surfaces were inspected visually for gross defects that would have adversely impacted strength and strain-to-failure results.

Preliminary fracture tests were performed on the neat resin according to ASTM D5045 in the single-edge notch bend (SENB) configuration using three $40 \mathrm{~mm}$ x $10 \mathrm{~mm}$ x $5 \mathrm{~mm}$ specimens that were initially machined with a $45^{\circ}$ disc cutter to 0.45 of the width and further notched with a razor blade. The final crack length was approximately half the width and accurately measured by microscopically inspecting the fractured specimens. The compressive load was applied using a 3-point bending jig at $0.5 \mathrm{~mm} \mathrm{~min}^{-1}$.

\section{Results and discussion}

\subsection{Nanocomposite production and composition}

The CNTs and thermosetting matrix were mixed by extrusion as it provides high shear, and is a continuous process that is readily scalable in volume. With careful monitoring of temperatures along the barrel of the extruder, runaway exotherms were avoided. The consistency of the extruded NC changed from a thin paste to pellets, with increasing CNT content. The highest CNT loading successfully extruded was $20 \mathrm{wt} \% / 13.6 \mathrm{vol} \%$, more than double the highest reported to date $(8 \mathrm{wt} \%)$ [15] for a thermosetting NC prepared by shear mixing. Typically, forming an extrudate with high CNT loadings into test specimens requires the $\mathrm{NC}$ to flow over large distances relative to the size of the CNT filler, producing agglomerates $[19,20]$. As such, powdering the NC reduced the flow distances when consolidating under pressure, while curing under vacuum removed air pockets that would otherwise yield a composite with voids.

The extruded NC was initially milled using two long grinding cycles of two minutes with a long re-cooling period in between of two minutes (blue, dashed curve in Figure 1a). This method proved ineffective as it yielded powder with a large average particle size $(\sim 60 \mu \mathrm{m})$ 
and broad distribution. Systematic variation of the grinding parameters showed that grinding cycles of $10 \mathrm{~s}$ and re-cooling for $40 \mathrm{~s}$ between them yielded powders (Figure 1b) with the smallest average particle size of $20 \mu \mathrm{m}$ (red, solid curve in Figure 1a). Powder particles presumably experienced less frictional heating during shorter grinding cycles and were sufficiently cooled in between cycles to avoid reaching temperatures exceeding $\mathrm{T}_{\mathrm{g}}$ and fusing into aggregates. In principle, more rapid cycles might be beneficial, but were not possible on the equipment used. The length distributions of the CNTs were measured after extrusion and grinding of the NCs (Figure 2). Interestingly, the lognormal distributions are equivalent within error across the range of CNT loadings, despite the variable viscosity, probably because the extrusion temperature was adjusted to maintain a similar torque during extrusion and/or as a result of the grinding step. Length distributions are not easily measured after curing, but it is reasonable to assume that there is little further change during consolidation, and an average CNT length $(430 \pm 250 \mathrm{~nm})$ was assumed in further analysis.

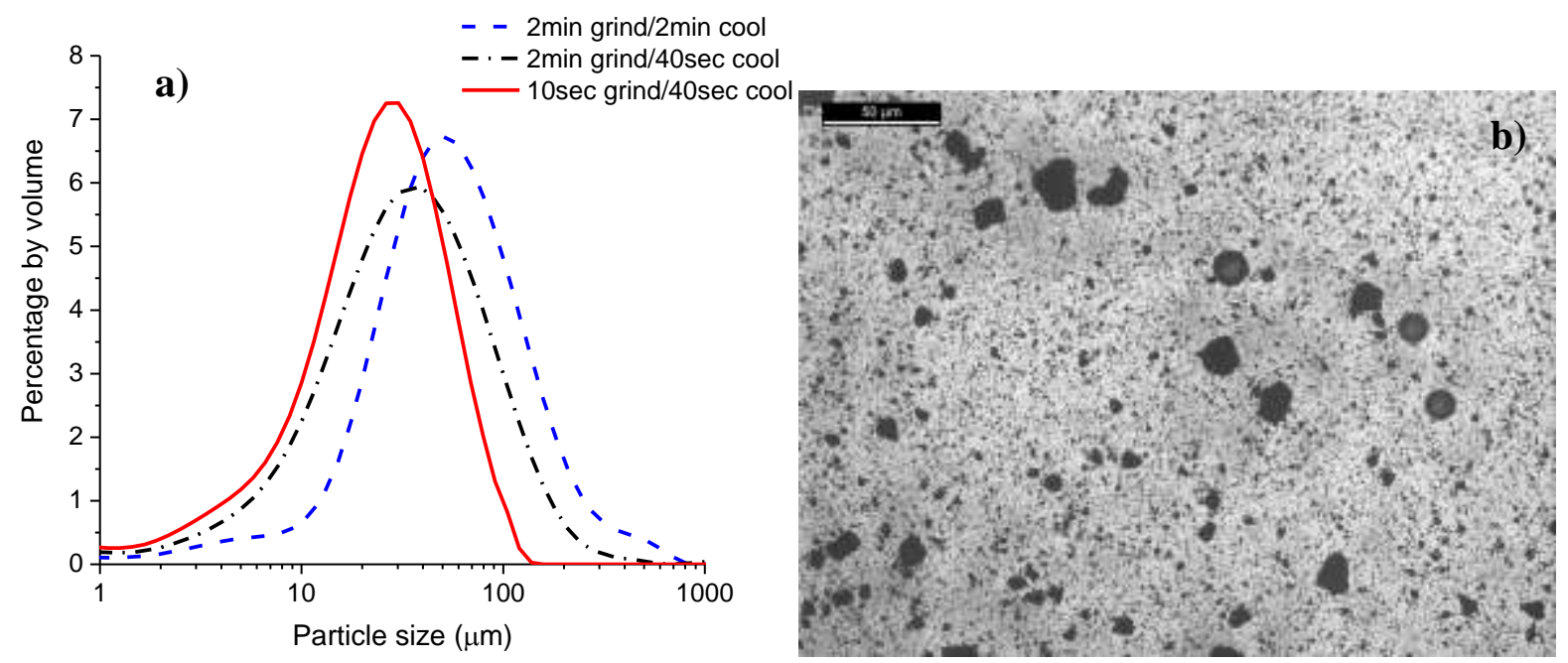

Figure 1. a) Particle size distribution and b) morphology of cryogenically milled powder containing 20 wt $\%$ CNTs. 

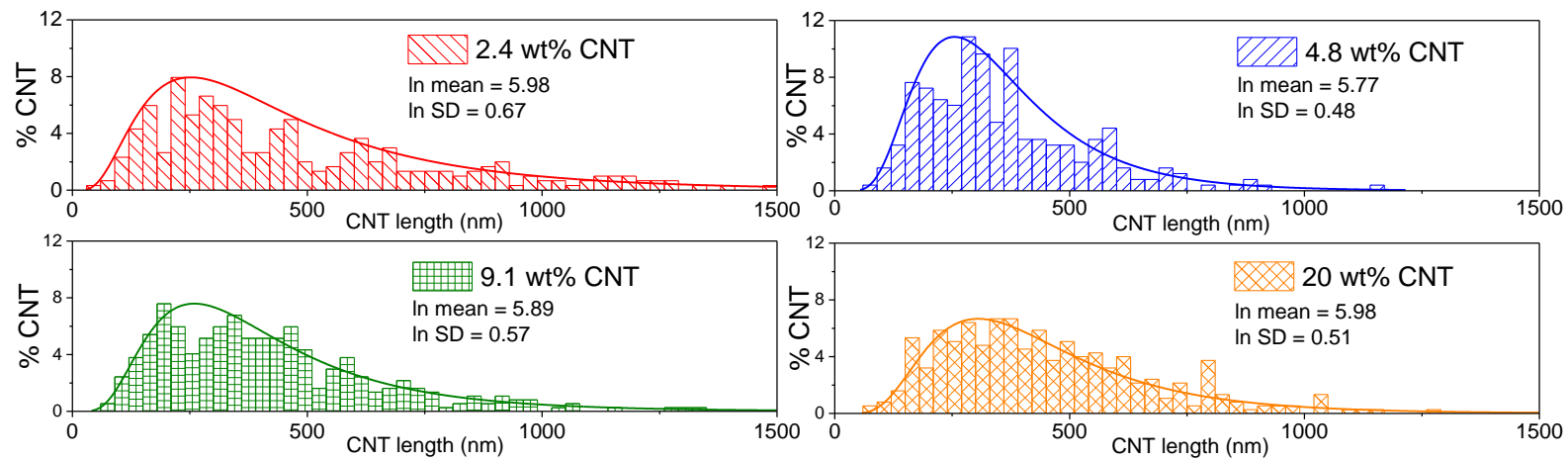

Figure 2. Length distributions (histograms) of CNTs after extrusion and grinding of the NCs, but before curing (to allow the CNTs to be separated). Lognormal distributions (lines) were found to fit best with fitting parameters for each population in the figure.

Macroscopically, the NC specimens were well formed across all CNT loadings (Figure 3a), with a good surface finish and no apparent defects. TGA analysis confirmed intended CNT weight fractions in the resin within the $1-2 \%$ error of the TGA; no changes in thermal stability were detected (Figure 3b). Whilst weight fractions can be measured during sample preparation and checked with TGA, CNT volume fractions are more relevant to most property comparisons. In principle, the conversion may not necessarily be straightforward, since the surface interactions involve a significant volume of the matrix, and the fate of the hollow nanotube core is uncertain; nevertheless, within the experimental error, CNT volume fractions in the NCs were adequately estimated using the measured matrix density of 1.2 $\mathrm{g} / \mathrm{cm}^{3}$ and a CNT density of $1.9 \mathrm{~g} / \mathrm{cm}^{3}$, which was deduced from a CNT density of $1.75 \mathrm{~g} / \mathrm{cm}^{3}$ [21] corrected for the $10 \mathrm{wt} \%$ metal catalyst content. The CNTs themselves could not be sufficiently compacted to fill at least one third of the pycnometer chamber and ensure an accurate direct density measurement. 
a)

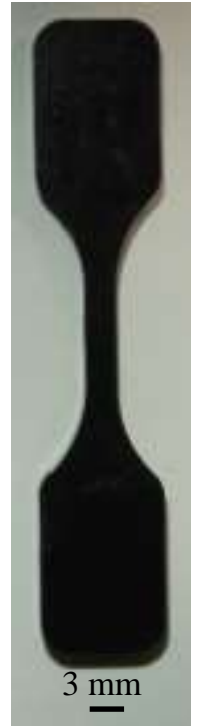

b)

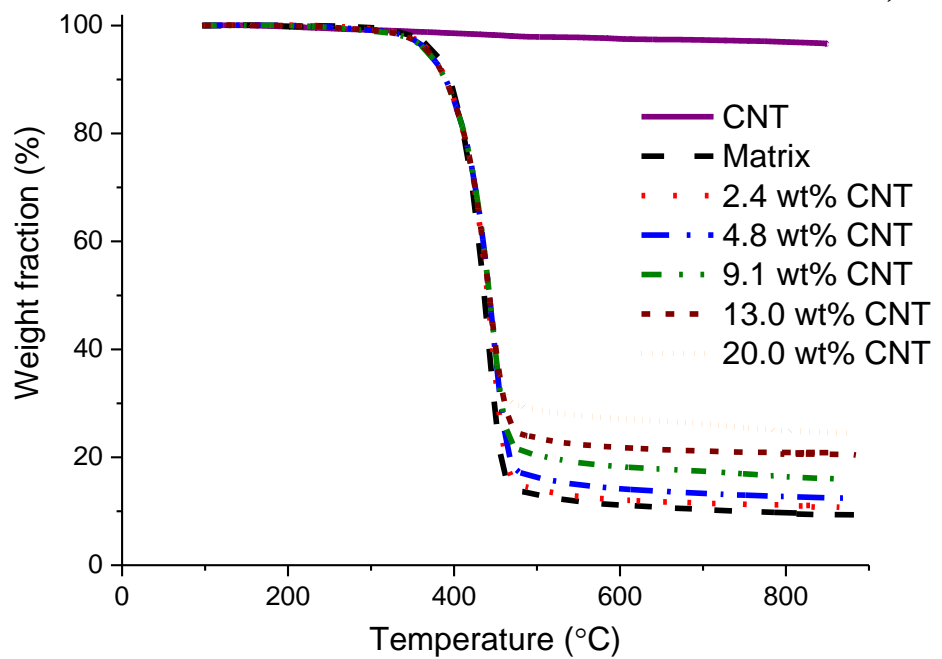

Figure 3. a) Well consolidated NC containing 13.6 vol\% CNTs, b) TGA of NCs in an $\mathrm{N}_{2}$ atmosphere used to deduce CNT weight fractions.

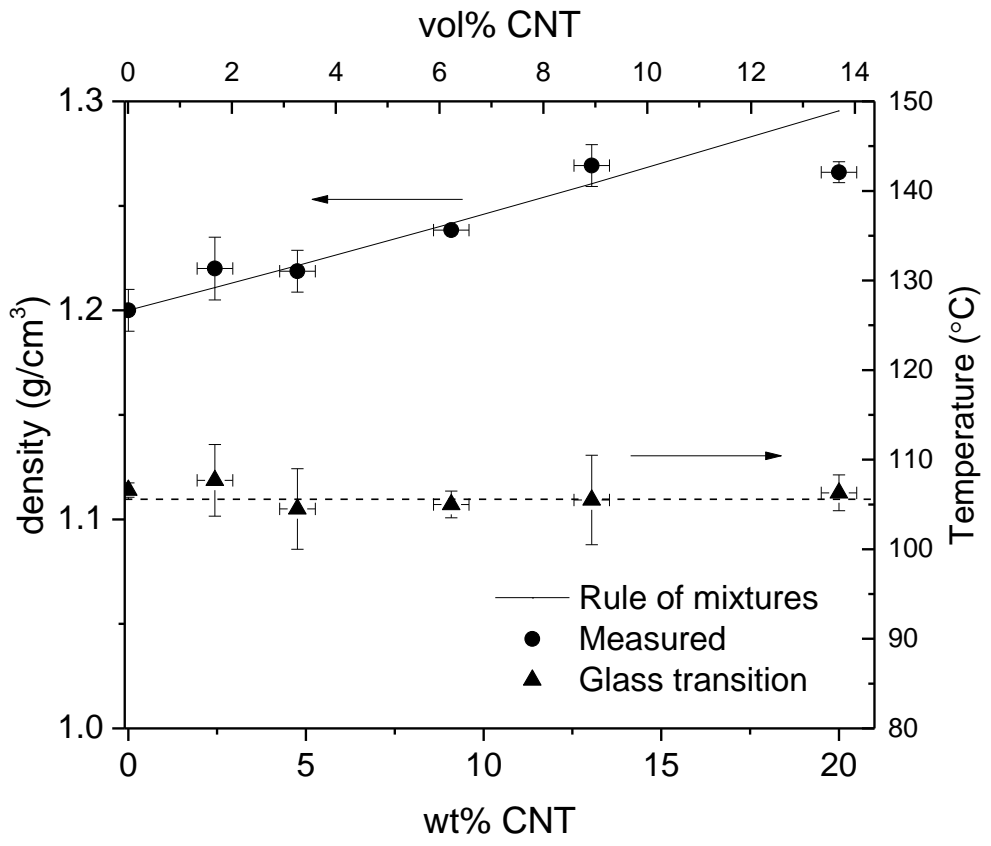

Figure 4. Measured densities of $\mathrm{NC}$ and as calculated by rule of mixtures and $\mathrm{T}_{\mathrm{g}}$ measured by DSC. Weight fractions are derived from TGA data, and volume fraction estimated as described in the text.

Assuming complete consolidation and no voids, expected NC densities were estimated using the rule of mixtures from volume fractions; porosity was calculated from the expected and measured densities. The rule of mixture densities generally compared well with those measured, following the expected linear trend (Figure 4), suggesting that complete consolidation was achieved, with the exception of the NCs containing 13.6 vol\% CNTs, 
which were estimated to contain 2 vol\% voids. DIC micrographs of polished sections appeared smooth at low CNT loadings (Figure 5a) while at the highest loading (Figure 5b) the microstructure appeared textured, with features on the scale of $50-100 \mu \mathrm{m}$, akin to that of the larger particles from the powder particle size distribution. It seems that the 13.6 vol\% CNT NC particles were not fully consolidated even at high pressures, presumably due to the high viscoelasticity of heavily CNT loaded polymers [4]. Some of the resin was pushed out of CNT rich regions locally to fill gaps between powder particles (Figure 5c), but the highly viscoelastic resin could not effectively migrate to fill areas with larger gaps, giving rise to localised voids.

The curing of all NCs follows the typical exotherm for epoxy curing reactions, including the well documented [18] acceleration effect with increasing CNT loading. No significant variability was observed in the final extents of reaction, suggesting that the degree of crosslinking was not affected by the presence of large CNT volumes, which was confirmed by the constant $\mathrm{T}_{\mathrm{g}}$ (Figure 4) across all NCs. 


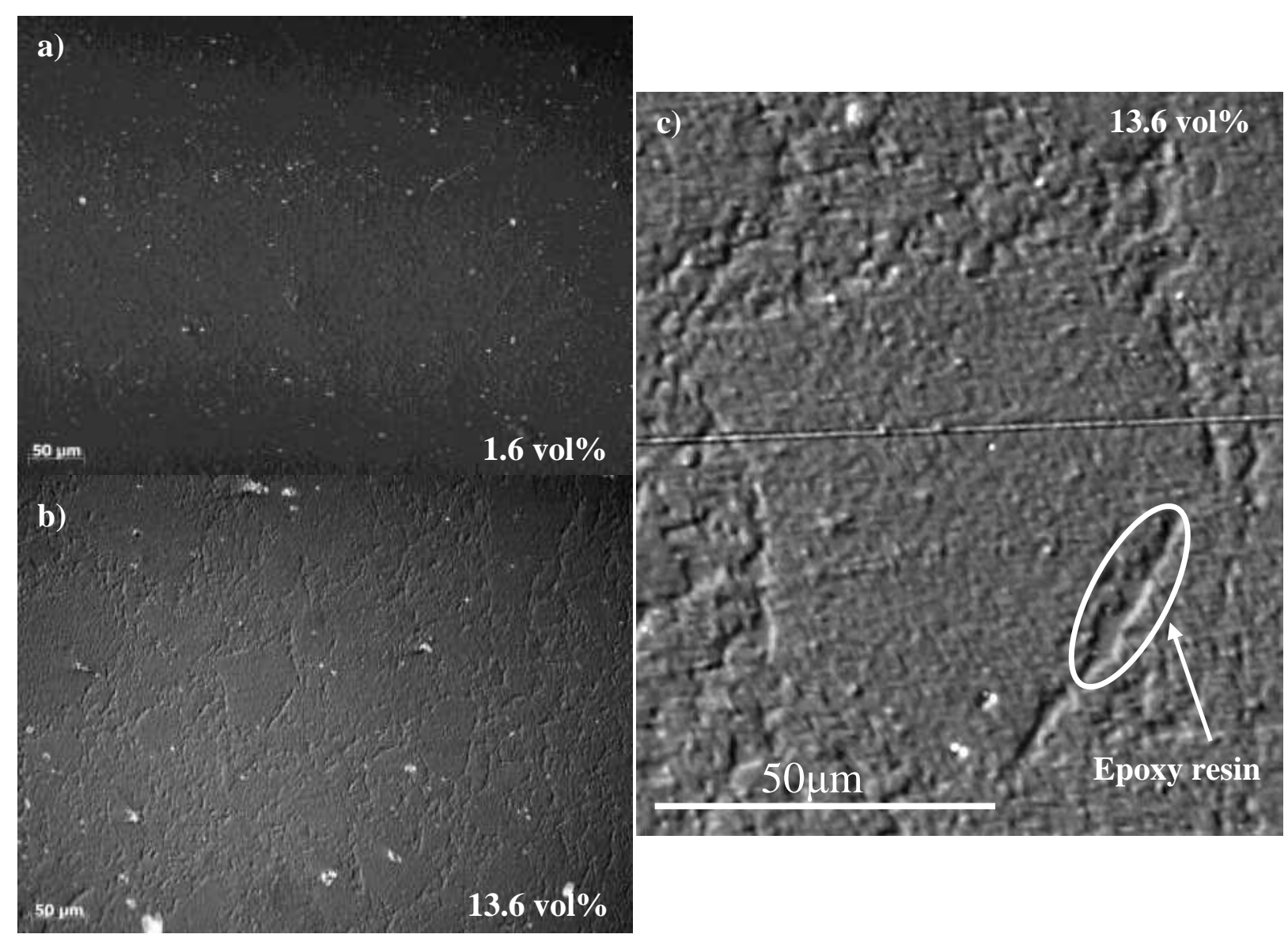

Figure 5. DIC optical micrographs of polished sections showing the microstructure of NCs with a) low and b,c) high CNT loadings. Contrast is a result of refraction index mismatch of CNT rich and CNT poor phases.

\subsection{Nanotube dispersion}

The ability of a process to disperse and distribute CNTs in a matrix is critical in reducing stress concentrations associated with agglomerates and thus achieving the full mechanical potential of NCs, particularly for mechanically entangled, industrial grade CNTs. For untreated MWCNTs in epoxy resins, agglomerates are typically a few micrometres in diameter and spaced tens of micrometres apart [15]. CNT agglomerates were not observed (Figure 6) and the CNTs, for the most part, appeared individualised (Figure 7). The matrix cones suggest a strong adhesion between the CNTs and the resin most likely associated with plastic deformation of the matrix during CNT pullout (Figure 7). Evidence of a good interface between the $\mathrm{NC}$ constituents is promising, especially with regards to stress transfer. 


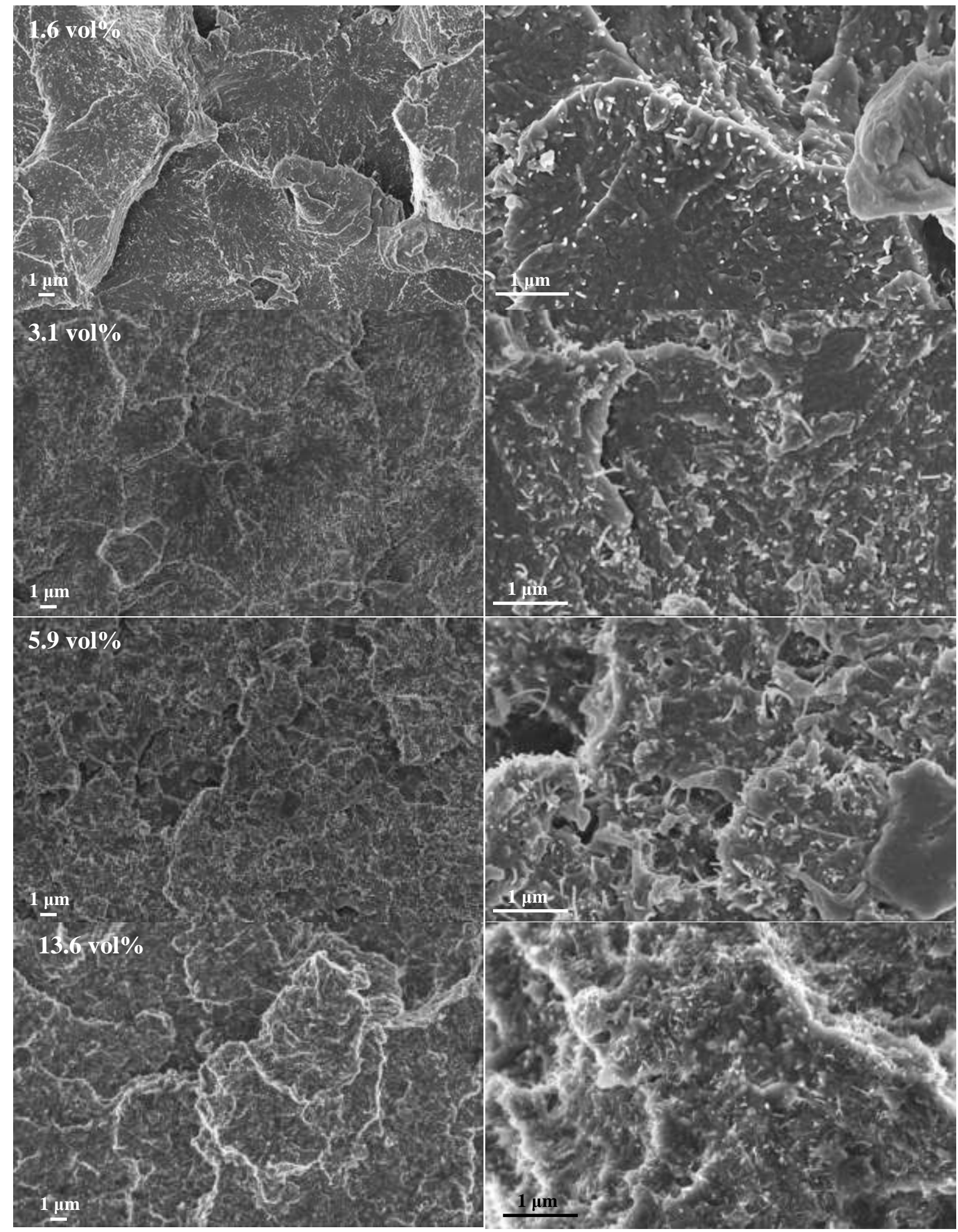

Figure 6. Low (left column) and high (right column) magnification SEM micrographs of NCs with different CNT loadings, as indicated. Samples depicted in the first three rows were sputter coated, while the last one was uncoated. 


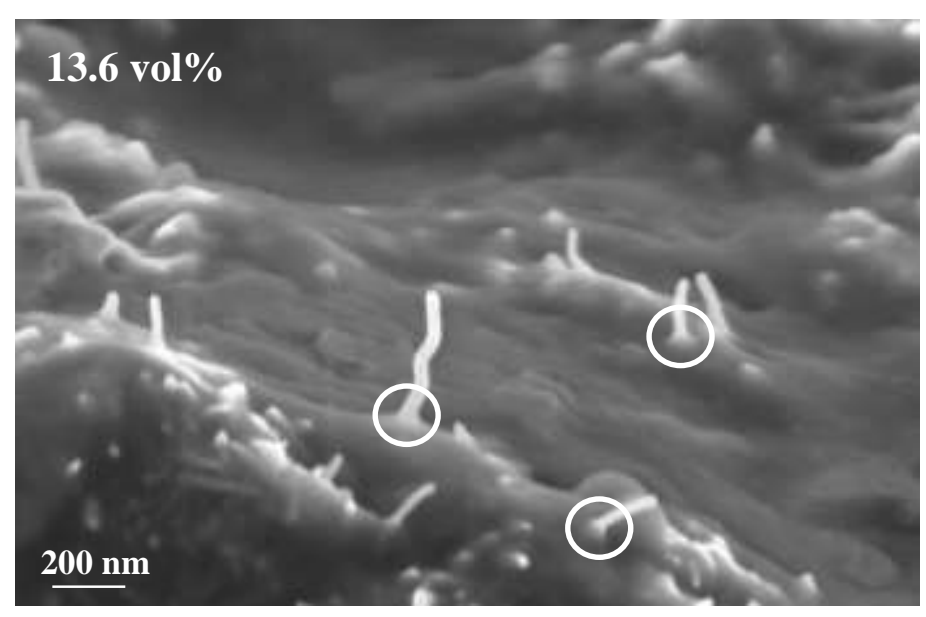

Figure 7. SEM of individual CNTs protruding from the NC fracture surface, with matrix cones highlighted. The measured pull-out length was at most $980 \mathrm{~nm}$ which is consistent with the measured length distribution.

\subsection{Nanocomposite electrical and thermal properties}

The electrical properties and behaviour of NCs have been extensively studied and reviewed $[22,23]$; both electrical percolation and the maximum DC conductivity have been shown to be strongly affected by CNT purity [24], aspect ratio [25], processing parameters [26, 27] and orientation [28-30]. The relationship between a perfect dispersion of fillers in a matrix and the percolation threshold has been formalised using the excluded volume concept $[31,32]$, and provides a means to qualify the CNT dispersion state, by comparing the calculated percolation threshold using the CNT aspect ratio to that measured.

$\sigma_{D C}$ was measured along three axes, two perpendicular $(\mathrm{X}$ and $\mathrm{Y})$ and one parallel $(\mathrm{Z})$ to the consolidation direction (inset of Figure 8). A $\sigma_{\mathrm{DC}}$ of $67 \pm 5 \mathrm{Sm}^{-1}$ was measured in both $\mathrm{X}$ and Y axes at the highest CNT loading of 13.6 vol\%. This value is about four times lower than the highest previously reported [15] for an epoxy based NC with $8 \mathrm{wt} \%$ randomly dispersed CNTs. It should be noted that the CNTs used in that work had larger aspect ratios (290 compared to 43 in this work) and processing was optimized by finding the shear rate which produces the $\mathrm{NC}$ with maximum $\sigma_{\mathrm{DC}}$.

The $\sigma_{\mathrm{DC}}$ (Figure 8 ) in the $\mathrm{X} / \mathrm{Y}$ and $\mathrm{Z}$ axes begin to diverge beyond CNT loadings of $\sim 6 \mathrm{vol} \%$. The difference would be consistent with CNT orientation induced during compression 
moulding not fully relaxing before curing due to increasing viscoelasticity of the NC with increasing CNT loading. As a result, the CNTs would have been preferentially aligned in the plane perpendicular to the direction of the applied force and the NC would have become increasingly anisotropic. This phenomenon is important to consider for characterizing both the percolating characteristics of the network and the micromechanical behaviour of the NC.

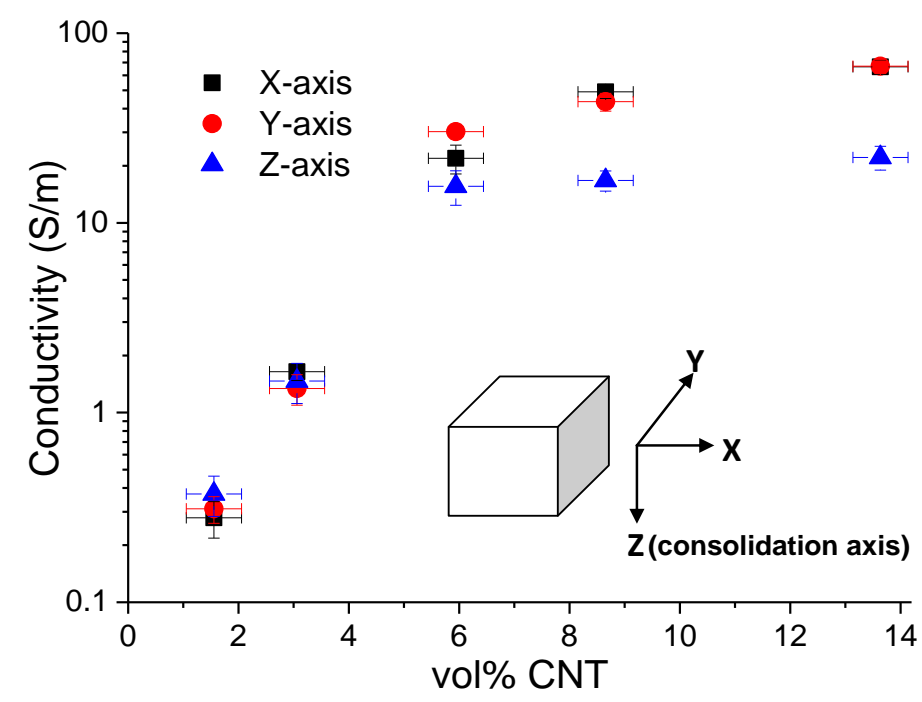

Figure 8. Electrical conductivity of NCs measured in three axes.

$$
\begin{gathered}
\sigma_{D C} \propto\left|\Phi-\Phi_{C}\right|^{t} \\
\Phi_{C}=1-\exp \left(-\frac{c V}{\left\langle V_{e}\right\rangle}\right)
\end{gathered}
$$

The datasets in Figure 8 were fitted with a power-law function [23] (Equation 1): where $\Phi$ is the nanotube volume fraction, $\Phi_{C}$ the nanotube volume fraction at the percolation threshold and $t$ parameter indicating network dimensionality. The fit yielded $\Phi_{\mathrm{C}}=1.85 \pm 0.70 \mathrm{vol} \%$ in all axes, $\mathrm{t}=1.37 \pm 0.40$ for the $\mathrm{X}$ and $\mathrm{Y}$ axis data, and $\mathrm{t}=1.01 \pm 0.28$ for the $\mathrm{Z}$ axis data; $\mathrm{a}$ value of $\mathrm{t}$ near 1.3 has been shown to correspond to anisotropic networks, with elements preferentially aligned in a plane [33]. Nonetheless, values of $t$ should be taken with caution as the degree of anisotropy is likely to vary. The general expression for calculating the percolation threshold according to the excluded volume concept is given by Equation 2: 
where $c$ is the total excluded volume of the system, $V$ the volume of the filler particle and $\left\langle V_{e}\right\rangle$ the excluded volume of an individual filler particle. [34] Using the average measured post-processed CNT length $(430 \pm 250 \mathrm{~nm})$, diameter $(10 \pm 3 \mathrm{~nm})$, and $\mathrm{c}=1.4$ and 2.8 for an isotropic and anisotropic system of capped cylinders [35], respectively, the excluded volume approach predicts $\Phi_{\mathrm{C}}=1.2$ and $2.4 \mathrm{vol} \%$. The calculated CNT percolation threshold values are within the range of those deduced from the fitted $\sigma_{\mathrm{DC}}$, supporting the interpretation from SEM micrographs that the processing method was effective in dispersing the CNTs in the matrix, which form a statistical network at low loadings.

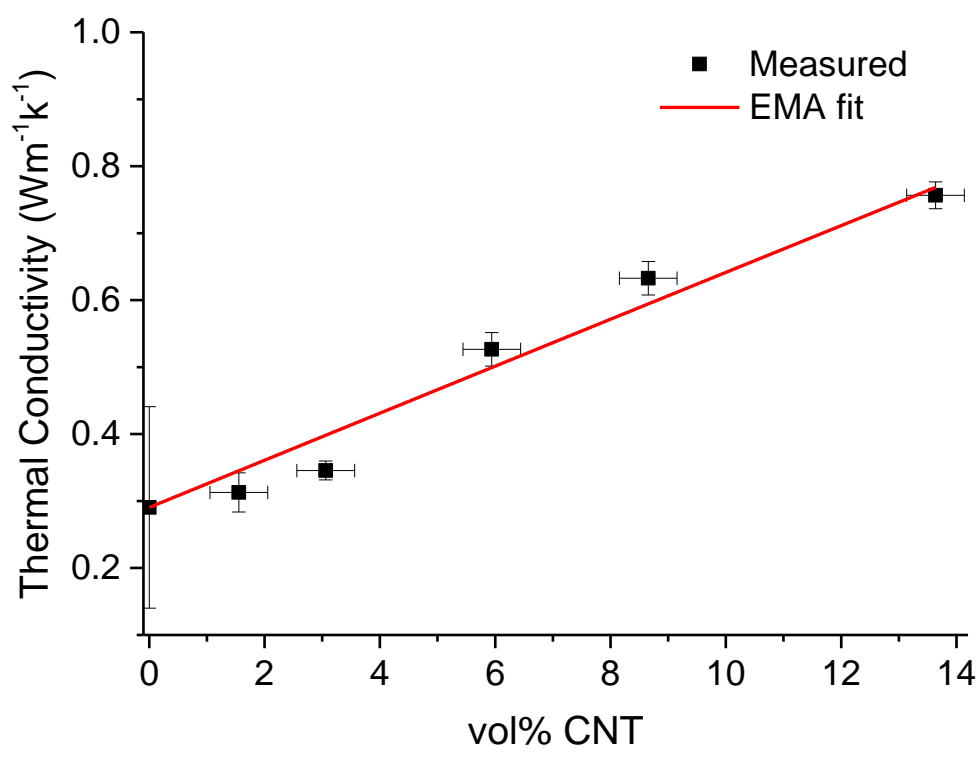

Figure 9. Thermal conductivity of NCs measured in the Z-axis.

The $\mathrm{k}$ of the NCs was measured in the Z-axis, parallel to the consolidation direction. The addition of 13.6 vol\% CNTs to the resin improved the $\mathrm{k}$ by $165 \%$ from 0.29 to $0.77 \mathrm{Wm}^{-1} \mathrm{~K}^{-1}$ (Figure 9). The trend is similar to the previous highest $\mathrm{k}$ reported [14] for shear mixed CNTepoxy NCs $\left(0.33 \mathrm{Wm}^{-1} \mathrm{~K}^{-1}\right.$ at $\left.5 \mathrm{wt} \% \mathrm{CNTs}\right)$, but greater in absolute terms due to the higher CNT volume fraction. A non-linear least squares fit of the data using the effective medium approach (EMA [36]) yields an interface thermal resistance value of $1.9 \times 10^{-8} \pm 10^{-9} \mathrm{~m}^{2} \mathrm{KW}^{-1}$, which falls within the $10^{-8} \mathrm{~m}^{2} \mathrm{KW}^{-1}$ order of magnitude theoretically calculated and measured $[37,38]$ for CNT-polymer interfaces. Furthermore, the $\mathrm{k}$ of the matrix used in this study $(0.29$ 
$\left.\mathrm{Wm}^{-1} \mathrm{~K}^{-1}\right)$ was appreciably higher than that typical for cured epoxy resins $\left(0.19 \mathrm{Wm}^{-1} \mathrm{~K}^{-1}\right.$

[38]) for which the relative improvement upon addition of a large fraction of CNTs should be even more significant. The current maximum measured value $\left(0.77 \mathrm{Wm}^{-1} \mathrm{~K}^{-1}\right)$ approaches the requisite range $\left(1-2 \mathrm{Wm}^{-1} \mathrm{~K}^{-1}[39]\right)$ for thermal interface materials (TIM) such as aluminium filled silicones used in heat dissipation applications.

\subsection{Nanocomposite mechanical properties}

In the majority of existing studies on NCs with randomly dispersed CNTs, Young's modulus $\left(\mathrm{E}_{\mathrm{NC}}\right)$ and strength $\left(\sigma_{\mathrm{NC}}\right)$ improved up to CNT loadings of a few volume percent, after which moduli plateaued $[40]$ and strengths sharply dropped $[6,41]$ due to inadequate processing resulting in CNT agglomerates that do not transfer stress efficiently and act as stress concentrators. Furthermore, NCs with large CNT loadings (> $5 \mathrm{wt} \%)$ are severely embrittled, with failure strains reduced by $100-200 \%$ [6].

In this work, $\mathrm{E}_{\mathrm{NC}}$ increased monotonically with increasing CNT volume fraction (Figure 10a) and the maximum $\sigma_{\mathrm{NC}}$ were achieved at the highest loading (Figure 10b). The 2 vol $\%$ of voids in the NC containing 13.6 vol\% CNTs are not thought to influence either modulus or strength significantly. These voids (Figure 11) were significantly smaller (10-30 $\mu \mathrm{m})$ than an estimate of the critical defect size $(c)$ for the resin $(\sim 500 \mu \mathrm{m})$, approximated from the Irwin definition of the stress intensity factor $(K)$ [42] (Equation 3); a $K$ of $1.18 \pm 0.05 \mathrm{MPa} \mathrm{m}^{1 / 2}$ was measured from preliminary fracture tests on the neat resin and $\sigma$ is the failure strength of the neat resin $(57.7 \pm 8.6 \mathrm{MPa})$. 

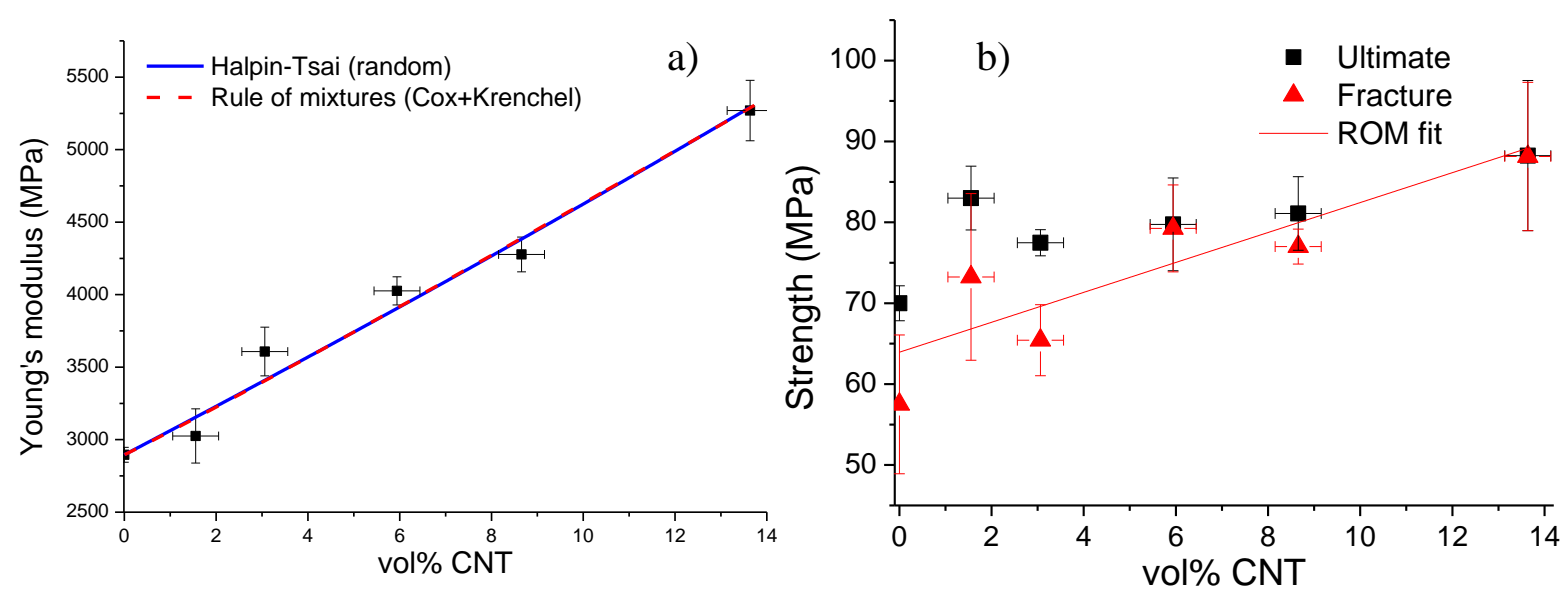

Figure 10. a) Young's modulus, b) ultimate and fracture strength values from tensile measurements of the NCs.

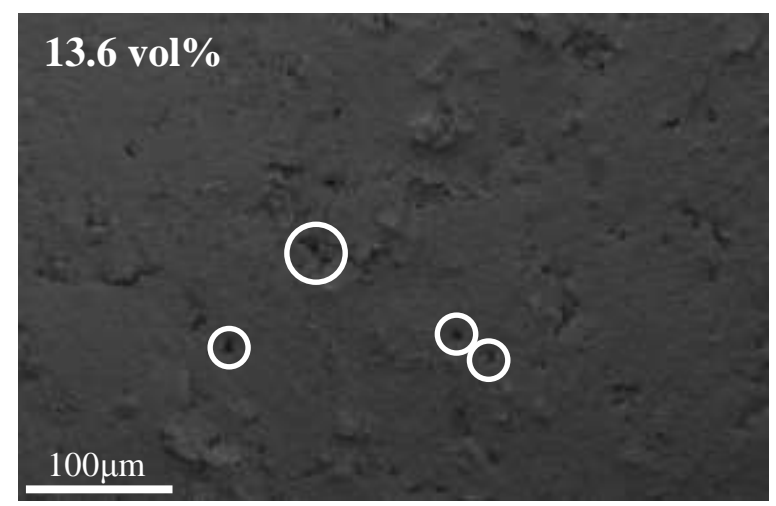

Figure 11. Fracture surface of an NC, where the highlighted features are voids.

$$
K=\sigma \sqrt{\pi c}
$$

The maximum $\mathrm{E}_{\mathrm{NC}}$ value of $5.4 \mathrm{GPa}$ is significant not only because it is the largest reported to date for a CNT-epoxy NC produced by shear mixing, but also because of the possibility to upgrade the performance of inexpensive resins. The reduction in failure strain (Figure 12a), despite the improved strength and stiffness is expected, and also frequently observed in thermoplastics with high CNT loadings [3]; the stiff reinforcing CNTs break or pull out at lower strain, transferring additional load to the matrix, leading to overall composite failure. Given their large surface area, and potential entanglement, CNTs may also directly restrict plastic flow of the surrounding resin-rich regions, particularly increasing CNT loadings. The improved trends and large $\mathrm{E}_{\mathrm{NC}}$ values can be attributed to the good CNT dispersion and distribution maintained throughout processing, which allow for more effective reinforcement and stress transfer using the relatively defective and short CNTs. 

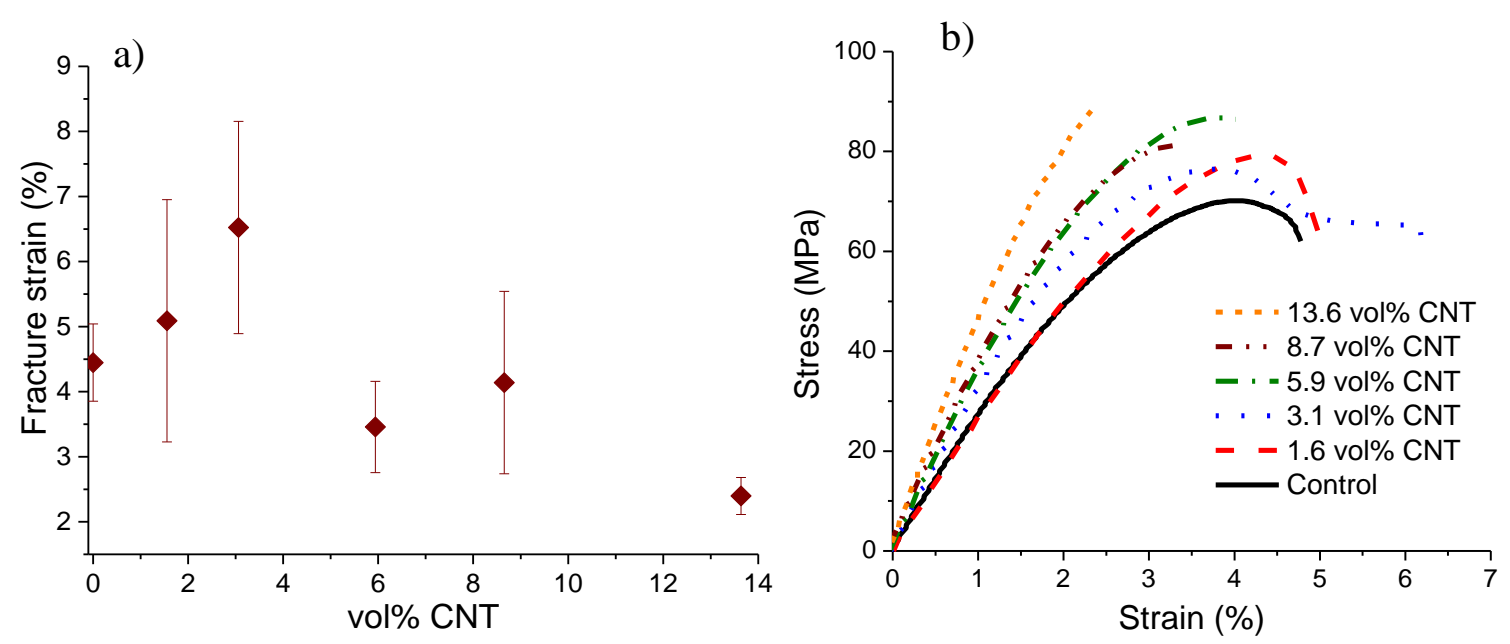

Figure 12. a) Fracture strains from tensile measurements of NCs and b) representative stress-strain curves.

The measured $\mathrm{E}_{\mathrm{NC}}$ as a function of CNT volume fraction were fitted with Halpin-Tsai [13] equations (Equation 4) for randomly oriented fibres, as well as the rule of mixtures with correction factors for length $\left(\eta_{L}^{E}\right)$ and orientation $\left(\eta_{O}^{E}\right)$ (Equation 5) as proposed by Cox [43] and Krenchel [44], respectively. A CNT modulus ( $\left.\mathrm{E}_{\mathrm{CNT}}\right)$ of $46 \pm 3 \mathrm{GPa}$ was determined by fitting experimental data with the Halpin-Tsai equations, and $65 \pm 5 \mathrm{GPa}$ using the rule of mixtures, assuming the CNT network was anisotropic $\left(\eta_{0}=0.375\right)$. These values compare well with those reported in the literature for highly defective, wavy, industrial grade MWCNTs [45-47].

$$
\begin{gathered}
\frac{E_{N C}}{E_{m}}=\frac{3}{8}\left(\frac{1+\zeta \eta_{\text {Long }} v_{f}}{1-\eta_{\text {Long }} v_{f}}\right)+\frac{5}{8}\left(\frac{1+2 \eta_{\text {Trans }} v_{f}}{1-\eta_{\text {Long }} v_{f}}\right) \\
\text { where } \eta_{\text {Long }}=\frac{\left(E_{C N T} / E_{m}\right)-1}{\left(E_{C N T} / E_{m}\right)+\zeta}, \eta_{\text {Trans }}=\frac{\left(E_{C N T} / E_{m}\right)-1}{\left(E_{C N T} / E_{m}\right)+2}, \zeta=2 \frac{l}{d} \\
E_{N C}=\eta_{O}^{E} \eta_{L}^{E} E_{C N T} v_{f}+E_{m}\left(1-v_{f}\right) \\
\sigma_{N C}=\eta_{O}^{\sigma} \eta_{L}^{\sigma} \sigma_{C N T} v_{f}+\sigma_{m}\left(1-v_{f}\right) \\
\tau_{I F S S}=\sigma_{C N T} \frac{r}{l_{c}}
\end{gathered}
$$

The NC fracture strength values at all loadings (triangles in Figure 12a) were also fitted with a modified rule of mixtures (Equation 6), with the orientation factor $\left(\eta_{O}^{\sigma}\right)$ also taken to be 
0.375 and the length factor $\left(\eta_{L}^{\sigma}\right)$ calculated to be 0.186 as prescribed in [48], using the CNT length distribution and critical length, as measured by SEM. A lower bound for the critical length $(1130 \pm 120 \mathrm{~nm})$ was estimated by doubling the average of the ten longest CNTs protruding from fracture surfaces. From the slope of the linear fit of the NC fracture strengths with Equation 6, a CNT strength of $2.9 \pm 0.6 \mathrm{GPa}$ was calculated, which agrees well with experimental results (3.6 GPa) for CVD grown CNTs [49]. The CNT-matrix interfacial shear strength (IFSS) was estimated from Equation 7, where $r$ is the CNT radius and $l_{c}$ the critical length. An IFSS of $12 \pm 9 \mathrm{MPa}$ was estimated, using the lower bound for critical length estimated from the SEM fractography, which agrees well with experimental results (20-40 MPa) obtained from pull-out tests [51].

\section{Conclusions}

A novel, readily scalable, powder based route for the fabrication of epoxy based nanocomposites with high CNT loadings (20 wt\%/13.6 vol\%) is presented. The process allowed the successful production of a dense material with excellent CNT dispersion and distribution, providing significantly improved mechanical properties $(\mathrm{E}=5.4 \mathrm{GPa}, \sigma=90$ $\mathrm{MPa}, \varepsilon=2.5 \%)$. Although the nanocomposites with the highest CNT loading contained some porosity (2 vol\%), the modulus and strength continued to increase. The high pressure consolidation process created an anisotropic CNT network, resulting in a material with large electrical $\left(67 \mathrm{Sm}^{-1}\right)$ and thermal $\left(0.77 \mathrm{Wm}^{-1} \mathrm{~K}^{-1}\right)$ conductivities relative to previous reports. Its mechanical and transport properties make the nanocomposite a candidate for multifunctional applications such as EMI shielding (in theory, $50 \mathrm{~dB}$ at $5 \mathrm{GHz}$ [52]) and thermal dissipation where mechanical performance is also critical.

Even though this processing route allows fabrication of NCs without CNT agglomerates, one of the intrinsic limitations to composite performance remains the quality of the filler. Further 
efforts should consider longer, straighter, more graphitic and generally higher quality CNTs.

Along with materials selection, the powder particle size also appears to be critical to successful consolidation and, therefore, performance of the material; the process could be improved by reducing and narrowing the distribution of powder particle sizes. In addition to its exciting intrinsic properties, the powdered nanocomposite is potentially an interesting feedstock for processes such as powder coating and powder prepregging $[53,54]$ where multifunctional performance is desired, particularly for carbon based hierarchical composites $[55]$.

\section{Acknowledgements}

The authors would like to thank Dstl for funding the research and Hexcel for supplying materials.

\section{References}

[1] Chou TW, Gao LM, Thostenson ET, Zhang ZG, Byun JH. An assessment of the science and technology of carbon nanotube-based fibers and composites. Compos Sci Technol. 2010;70(1):1-19.

[2] Yoon H, Yamashita M, Ata S, Futaba DN, Yamada T, Hata K. Controlling exfoliation in order to minimize damage during dispersion of long SWCNTs for advanced composites. Sci Rep-Uk. 2014;4.

[3] Sandler J, Werner P, Shaffer MSP, Demchuk V, Altstadt V, Windle AH. Carbonnanofibre-reinforced poly(ether ether ketone) composites. Compos Part a-Appl S. 2002;33(8):1033-1039.

[4] Bangarusampath DS, Ruckdaschel H, Altstadt V, Sandler JKW, Garray D, Shaffer MSP. Rheology and properties of melt-processed poly(ether ether ketone)/multi-wall carbon nanotube composites. Polymer. 2009;50(24):5803-5811.

[5] Guadagno L, Vertuccio L, Sorrentino A, Raimondo M, Naddeo C, Vittoria V, et al. Mechanical and barrier properties of epoxy resin filled with multi-walled carbon nanotubes. Carbon. 2009;47(10):2419-2430.

[6] Yeh MK, Hsieh TH, Tai NH. Fabrication and mechanical properties of multi-walled carbon nanotubes/epoxy nanocomposites. Mat Sci Eng a-Struct. 2008;483:289-292.

[7] Seyhan AT, Gojny FH, Tanoglu M, Schulte K. Critical aspects related to processing of carbon nano tube/unsaturated thermoset polyester nanocomposites. Eur Polym J. 2007;43(2):374-379.

[8] Feng QP, Yang JP, Fu SY, Mai YW. Synthesis of carbon nanotube/epoxy composite films with a high nanotube loading by a mixed-curing-agent assisted layer-by-layer method and their electrical conductivity. Carbon. 2010;48(7):2057-2062. 
[9] Spitalsky Z, Tsoukleri G, Tasis D, Krontiras C, Georga SN, Galiotis C. High volume fraction carbon nanotube-epoxy composites. Nanotechnology. 2009;20(40):1-7.

[10] Cheng QF, Wang JP, Wen JJ, Liu CH, Jiang KL, Li QQ, et al. Carbon nanotube/epoxy composites fabricated by resin transfer molding. Carbon. 2010;48(1):260-266.

[11] Cebeci H, de Villoria RG, Hart AJ, Wardle BL. Multifunctional properties of high volume fraction aligned carbon nanotube polymer composites with controlled morphology. Compos Sci Technol. 2009;69(15-16):2649-2656.

[12] Bradford PD, Wang X, Zhao HB, Maria JP, Jia QX, Zhu YT. A novel approach to fabricate high volume fraction nanocomposites with long aligned carbon nanotubes. Compos Sci Technol. 2010;70(13):1980-1985.

[13] Gojny FH, Wichmann MHG, Kopke U, Fiedler B, Schulte K. Carbon nanotubereinforced epoxy-compo sites: enhanced stiffness and fracture toughness at low nanotube content. Compos Sci Technol. 2004;64(15):2363-2371.

[14] Thostenson ET, Chou TW. Processing-structure-multi-functional property relationship in carbon nanotube/epoxy composites. Carbon. 2006;44(14):3022-3029.

[15] Rosca ID, Hoa SV. Highly conductive multiwall carbon nanotube and epoxy composites produced by three-roll milling. Carbon. 2009;47(8):1958-1968.

[16] Menzel R. Developing gas-phase methodologies for the modification and characterisation of carbon nanotube surfaces PhD. Imperial College London, 2009.

[17] Adams RC. ASM handbook Vol. 21, Composites. ASM International; 2001.

[18] Puglia D, Valentini L, Kenny JM. Analysis of the cure reaction of carbon nanotubes/epoxy resin composites through thermal analysis and Raman spectroscopy. J Appl Polym Sci. 2003;88(2):452-458.

[19] Pötschke P, Fornes TD, Paul DR. Rheological behavior of multiwalled carbon nanotube/polycarbonate composites. Polymer. 2002;43(11):3247-3255.

[20] Tran MQ, Shaffer MSP, Bismarck A. Manufacturing carbon nanotube/PVDF nanocomposite powders. Macromol Mater Eng. 2008;293(3):188-193.

[21] Shaffer MSP, Windle AH. Fabrication and characterization of carbon nanotube/poly(vinyl alcohol) composites. Adv Mater. 1999;11(11):937-941.

[22] Al-Saleh MH, Sundararaj U. A review of vapor grown carbon nanofiber/polymer conductive composites. Carbon. 2009;47(1):2-22.

[23] Bauhofer W, Kovacs JZ. A review and analysis of electrical percolation in carbon nanotube polymer composites. Compos Sci Technol. 2009;69(10):1486-1498.

[24] Kim YJ, Shin TS, Choi HD, Kwon JH, Chung YC, Yoon HG. Electrical conductivity of chemically modified multiwalled carbon nanotube/epoxy composites. Carbon. 2005;43(1):23-30.

[25] Bai JB, Allaoui A. Effect of the length and the aggregate size of MWNTs on the improvement efficiency of the mechanical and electrical properties of nanocomposites experimental investigation. Compos Part a-Appl S. 2003;34(8):689-694.

[26] Martin CA, Sandler JKW, Shaffer MSP, Schwarz MK, Bauhofer W, Schulte K, et al. Formation of percolating networks in multi-wall carbon-nanotube-epoxy composites. Compos Sci Technol. 2004;64(15):2309-2316.

[27] Kovacs JZ, Velagala BS, Schulte K, Bauhofer W. Two percolation thresholds in carbon nanotube epoxy composites. Compos Sci Technol. 2007;67(5):922-928.

[28] Rahatekar SS, Hamm M, Shaffer MSP, Elliott JA. Mesoscale modeling of electrical percolation in fiber-filled systems. J Chem Phys. 2005;123(13).

[29] Felisberto M, Arias-Duran A, Ramos JA, Mondragon I, Candal R, Goyanes S, et al. Influence of filler alignment in the mechanical and electrical properties of carbon nanotubes/epoxy nanocomposites. Physica B. 2012;407(16):3181-3183. 
[30] Du FM, Fischer JE, Winey KI. Effect of nanotube alignment on percolation conductivity in carbon nanotube/polymer composites. Phys Rev B. 2005;72(12).

[31] Balberg I, Anderson CH, Alexander S, Wagner N. Excluded Volume and Its Relation to the Onset of Percolation. Phys Rev B. 1984;30(7):3933-3943.

[32] Celzard A, McRae E, Deleuze C, Dufort M, Furdin G, Mareche JF. Critical concentration in percolating systems containing a high-aspect-ratio filler. Phys Rev B. 1996;53(10):6209-6214.

[33] Stauffer D, Aharony A. Introduction to percolation theory. Rev. 2nd ed ed. London: Taylor \& Francis; 1994.

[34] Balberg I. Excluded-Volume Explanation of Archie Law. Phys Rev B. 1986;33(5):36183620.

[35] Balberg I. Universal Percolation-Threshold Limits in the Continuum. Phys Rev B. 1985;31(6):4053-4055.

[36] Nan CW, Liu G, Lin YH, Li M. Interface effect on thermal conductivity of carbon nanotube composites. Appl Phys Lett. 2004;85(16):3549-3551.

[37] Huxtable ST, Cahill DG, Shenogin S, Xue LP, Ozisik R, Barone P, et al. Interfacial heat flow in carbon nanotube suspensions. Nat Mater. 2003;2(11):731-734.

[38] Han ZD, Fina A. Thermal conductivity of carbon nanotubes and their polymer nanocomposites: A review. Prog Polym Sci. 2011;36(7):914-944.

[39] Prasher RS, Shipley J, Prstic S, Koning P, Wang JL. Thermal resistance of particle laden polymeric thermal interface materials. J Heat Trans-T Asme. 2003;125(6):1170-1177.

[40] Coleman JN, Khan U, Blau WJ, Gun'ko YK. Small but strong: A review of the mechanical properties of carbon nanotube-polymer composites. Carbon. 2006;44(9):16241652 .

[41] Li XF, Lau KT, Yin YS. Mechanical properties of epoxy-based composites using coiled carbon nanotubes. Compos Sci Technol. 2008;68(14):2876-2881.

[42] Hull D, Clyne TW. An introduction to composite materials. 2nd ed. Cambridge: Cambridge University Press; 1996.

[43] Cox HL. The elasticity and strength of paper and other fibrous materials. British Journal of Applied Physics. 1952;3(3):72.

[44] Krenchel H. Fibre reinforcement: theoretical and practical investigations of the elasticity and strength of fibre-reinforced materials. Copenhagen: Akademisk forlag; 1964.

[45] Gaillard J, Skove M, Rao AM. Mechanical properties of chemical vapor depositiongrown multiwalled carbon nanotubes. Appl Phys Lett. 2005;86(23).

[46] Salvetat JP, Kulik AJ, Bonard JM, Briggs GAD, Stockli T, Metenier K, et al. Elastic modulus of ordered and disordered multiwalled carbon nanotubes. Adv Mater. 1999;11(2):161-165.

[47] Lukic B, Seo JW, Bacsa RR, Delpeux S, Beguin F, Bister G, et al. Catalytically grown carbon nanotubes of small diameter have a high Young's modulus. Nano Lett. 2005;5(10):2074-2077.

[48] Fu SY, Lauke B. Effects of fiber length and fiber orientation distributions on the tensile strength of short-fiber-reinforced polymers. Compos Sci Technol. 1996;56(10):1179-1190.

[49] Xie SS, Li WZ, Pan ZW, Chang BH, Sun LF. Mechanical and physical properties on carbon nanotube. J Phys Chem Solids. 2000;61(7):1153-1158.

[50] Kelly A, Tyson WR. Tensile properties of fibre-reinforced metals: Copper/tungsten and copper/molybdenum. Journal of the Mechanics and Physics of Solids. 1965;13(6):329-350.

[51] Barber AH, Cohen SR, Eitan A, Schadler LS, Wagner HD. Fracture transitions at a carbon-nanotube/polymer interface. Adv Mater. 2006;18(1):83-87.

[52] Colaneri NF, Shacklette LW. Emi Shielding Measurements of Conductive Polymer Blends. Ieee T Instrum Meas. 1992;41(2):291-297. 
[53] Ho KKC, Shamsuddin SR, Riaz S, Lamorinere S, Tran MQ, Javaid A, et al. Wet impregnation as route to unidirectional carbon fibre reinforced thermoplastic composites manufacturing. Plast Rubber Compos. 2011;40(2):100-107.

[54] Karger J, Vodermayer A. A New Material Captures the Market. Sulzer Technical Review, vol. 21999. p. 4-7.

[55] Qian H, Greenhalgh ES, Shaffer MSP, Bismarck A. Carbon nanotube-based hierarchical composites: a review. J Mater Chem. 2010;20(23):4751-4762. 